\section{TÀI LIÊU THAM KHẢO}

1. Nông Hồng Lê, Nguyễn Ngọc Minh (2013). Nghiên cứu vô sinh do tắc vòi tứ cung và tìm hiêu một số yếu tố ảnh hưởng tại Bệnh viện Phụ Sản Trung ương. Tạp Chí Phu sản, 11(2), 136-138.

2. Bùi Thị Phương Nga (2000), "Nghiên cứu phẫu thuật nội soi điều trị vô sinh do vòi trứng - dính phúc mạc", Luận án Tiến sỹ y học. Trường Đại học Y Dược, Thành phố Hồ Chí Minh.

3. Cao Ngọc Thanh (2011), "Vô sinh do vòi tử cung - phúc mạc", Nhà xuất bản Giáo dục.
4. Nguyễn Thị Thảo (2011), Nghiên cứu một số yếu tố nguy cơ và ảnh hưởng của vô sinh do vòi tử cung đến phụ nữ taii Thanh Hóa, Luận án Tiến sỹ, Trướng Đại học $Y$ tể công cộng.

5. Garolla A., Pizzol D., Roberto A. et al; "Practical clinical and diagnostic pathway for the investigation of the infertile coupe"; Endocrinol.,January 2021 | https://doi.org/ 10.3389/fendo.2020.591837

6. Luttjeboer F, Havada T, Hughes E et al. Tubal flushing for subfertility. Cochrane Database Syst Rev 2007(3);CD 003718.

\title{
ĐÁNH GIÁ KẾT QUẢ CỦA PHƯƠ'NG PHÁP ĐĂT NộI KHÍ QUẢN NHANH THEO TRÌNH TỰ (RSI) CHO BÊ̂NH NHÂN CẤP CỨU
}

\author{
Nguyễn Minh Hiếu*, Nguyễn Văn Chi*, Trịnh Văn Đồng*
}

\section{TÓM TẮT}

Mục tiêu: Đánh giá kết quả của phương pháp đặt nội khí quản nhanh theo trình tự so với phương pháp đẳt nội khí quản không dùng thuốc giãn cơ. Phương pháp: Nghiên cứu mô tả cắt ngang 63 tại Trung tâm cấp cứu A9 Bệnh viện Bach Mai được đặt nội khí quản theo phương pháp nhanh theo trình tự và không dùng thuốc giãn cơ. Kết quả: Nhóm bệnh lý phổ biến nhất là tiêu hóa $(33 \%)$ và hô hấp $(31 \%)$. Tỳ lệ đặt nội khí quản thành công lần đâuu theo phương pháp RSI $(88 \%)$ cao hơn so với non - RSI $(67 \%)$, sự khác biêt này có ý nghĩa thống kê $(p<0,05)$. Thới gian đặt nội khí quản của nhóm đă̆t theo phương pháp RSI (76 giây) ngắn hơn so với nhóm non - RSI (163 giây), sự khác biệt này có ý nghĩa thống kê $(p<0,05)$. Tỷ lệ tụt huyết áp trong quá trình đặt nội khí quản ở nhóm non - RSI là cao hơn so với nhóm RSI và sư khác biêt này có ý nghĩa thống kê $(p<0,05)$. Các biển cố khác tổn thương miêng, họng, đặt nội khí quản quá sâu, đặt nội khí quản vào thực quản, trào ngược, nôn, rách cuff, tut $\mathrm{SpO}_{2}$ trong quá trình thức hiên có sư khác biệt chưa có ý nghĩa thống kê giữa 2 nhóm $(p>0,05)$. Kểt luận: Phương pháp đặt nội khí quản nhanh theo trình tự với ketamine và rocuronium áp dụng với những bệnh nhân cấp cứu không có yếu tố tiên lượng đường thở khó giảm thời gian, tăng tỷ lệ thành công lân đầu và không làm tăng các biến cố trong quá trình thực hiện so với những bệnh nhân không dùng giãn cơ.

Tư khóa: đặt nội khí quản nhanh theo trình tự, an thần, giãn cơ

\section{SUMMARY \\ ASSESSMENT OF RAPID SEQUENCE INTUBATION (RSI) IN EMERGENCY PATIENTS}

\footnotetext{
*Trường Đại học Y Hà Nội

Chịu trách nhiệm chính: Nguyễn Minh Hiếu

Email: hieu1203@gmail.com

Ngày nhận bài: 13.9.2021

Ngày phản biên khoa họ: 11.11.2021

Ngày duyệt bài: 18.11.2021
}

Objective: Compare between rapid sequence intubation and intubation without using neuromuscular blocking drugs. Method: Descriptive study on 63 patients in Emergency Center, Bach Mai Hospital, who received tracheal intubation in two methods rapid sequence intubation and intubation without using neuromuscular blocking drugs. Results: The most popular diseases were digestive (33\%) and respiratory diseases (31\%). Intubations with RSI had a higher success rate on the first attempt compared to those with non-RSI ( 88 vs $67 \%, p<0,05$ ). It took less time to perform intubation with RSI compared to those with non-RSI (76s vs 163s, $\mathrm{p}<0,05$ ). Hypotension rate in non-RSI group was higher than that in RSI group $(p<0,05)$. Other complications such as mouth, throat trauma, esophageal intubation, main stem bronchial intubation, regurgitation, vomiting, cuff failure and hypoxemia in procedure did not have statistically significant difference between two group RSI and non - RSI ( $p>0,05)$. Conclusion: Rapid sequence intubation method with ketamine and rocuronium in emergency patients, who do not have difficult airway, associated with shorter time to perform endotracheal intubation, higher success rate on the first attempt but not with the risk of complications compare with intubation without neuromuscular blocking drugs.

Keywords: rapid sequence intubation, sedative, neuromuscular blocking drug

\section{I. ĐẶT VẤN ĐỀ}

Đặt nội khí quản là thủ thuật cơ bản, có ý nghĩa sống còn, là một trong những thủ thuật được thực hiện nhiều nhất trong cấp cứu. Tuy nhiên, đặt nội khí quản không phải lúc nào cũng dễ dàng và có thể gặp rất nhiều tai biến trong thực hiện như chấn thương miệng họng, gãy răng, trào ngược dịch vị... Ở các nước có nền y học phát triển, đặt nội khí quản nhanh theo trình tự (Rapid Sequence Intubation) là phương pháp phổ biến nhất, trong đó các thuốc an thần và giãn cơ được sử dụng để tạo điều kiện tối ưu cho 
quá trình đặt nội khí quản ${ }^{1}$. Tại Việt Nam, kỹ thuật này đã được áp dụng phổ biến trong gây mê, tuy nhiên hiện chưa có nhiều nghiên cứu về áp dụng trong cấp cứu. Vì vậy, chúng tôi tiến hành nghiên cứu "Đánh giá kết quả của phương pháp đặt nội khí quản nhanh theo trình tự (RSI) cho bệnh nhân cấp cứu" với mục tiêu: Đánh giá kêt quả của phương pháp đặt nội khí quản nhanh theo trinh tự so với phương pháp đặt nội khí quản không dùng thuốc giãn cơ.

II. ĐỐI TƯợNG VÀ PHƯƠNG PHÁP NGHIÊN CỨU

2.1. Địa điểm và thời gian nghiên cứu: Trung tâm cấp cứu A9 Bệnh viện Bạch Mai năm từ năm 2020 đến năm 2021.

2.2. Đối tượng nghiên cứu:

- Tiêu chuẩn lựa chọn: Bệnh nhân đủ 18 tuổi điều trị tại Trung tâm cấp cứu A9 Bệnh viện Bạch Mai có chỉ định đặt nội khí quản cấp cứu, người đại diện của bệnh nhân đồng ý thực hiện thủ thuật.

- Tiêu chuẩn loại trừ: Bệnh nhân đặt nội khí quản trong tình trạng ngừng tuân hoàn hoặc có trên 2 yếu tố tiên lượng đường thở khó theo điểm LEMON².

\subsection{Quy trình nghiên cứu}

- Lựa chọn bệnh nhân có chỉ định đặt nội khí quản cấp cứu và không có quá 2 yếu tố tiên lượng đường thở khó. Giải thích về thủ thuật cho gia đình bệnh nhân để người đại diện của bệnh nhân lựa chọn phương pháp đặt nội khí quản.
- Tiến hành quy trình đặt nội khí quản theo 2 nhóm

- Nhóm đặt nội khí quản nhanh theo trình tự (RSI): Quy trình gôm 7 bước, chuẩn bị bệnh nhân, cụng cụ; dự trữ oxy; tối ưu bệnh nhân; an thân và giãn cơ bằng ketamine và rocuronium; điêuu chỉnh tư thế; đặt nội khí quản, kiểm tra; xử lý sau đặt nội khí quản.

- Nhóm đặt nội khí quản không dùng giãn cơ (Non - RSI): Áp dụng theo quy trình trước đây gồm chuẩn bị bệnh nhân, dụng cụ; dùng an thân, giảm đau; bóp bóng qua mặt nạ; đặt nội khí quản, kiểm tra; xử lý sau đặt nội khí quản.

2.3. Phương pháp nghiên cứu: Nghiên cứu mô tả cắt ngang kết hợp kĩ thuật thu thập số liệu quan sát.

Cỡ mẫu: 63 bênh nhân

Cách chọn mẩu: chọn mẫu thuận tiện.

Biến số và chỉ số nghiên cứu: nhóm bệnh lý, số lần thực hiện đặt nội khí quản, thời gian đặt nội khí quản, biến cố xảy ra trong quá trình đặt nội khí quản

2.5. Xử lý số liệu: Các số liệu được xử lý bằng phân mềm thống kê SPSS.

2.6. Đạo đức nghiên cứu. Phương pháp đặt nội khí quản nhanh theo trình tự đã được áp dụng phổ biến tại nhiều nơi. Người đại diện của bệnh nhân được giải thích đây đủ lợi ích, nguy cớ và đồng ý thực hiện. Số liệu thu thập được giúp cho các nhà lâm sàng cải thiện phương pháp đặt nội khí quản, nâng cao hiệu quả và giảm tai biến của thủ thuật.

\section{KẾT QUẢ NGHIÊN CỨU}

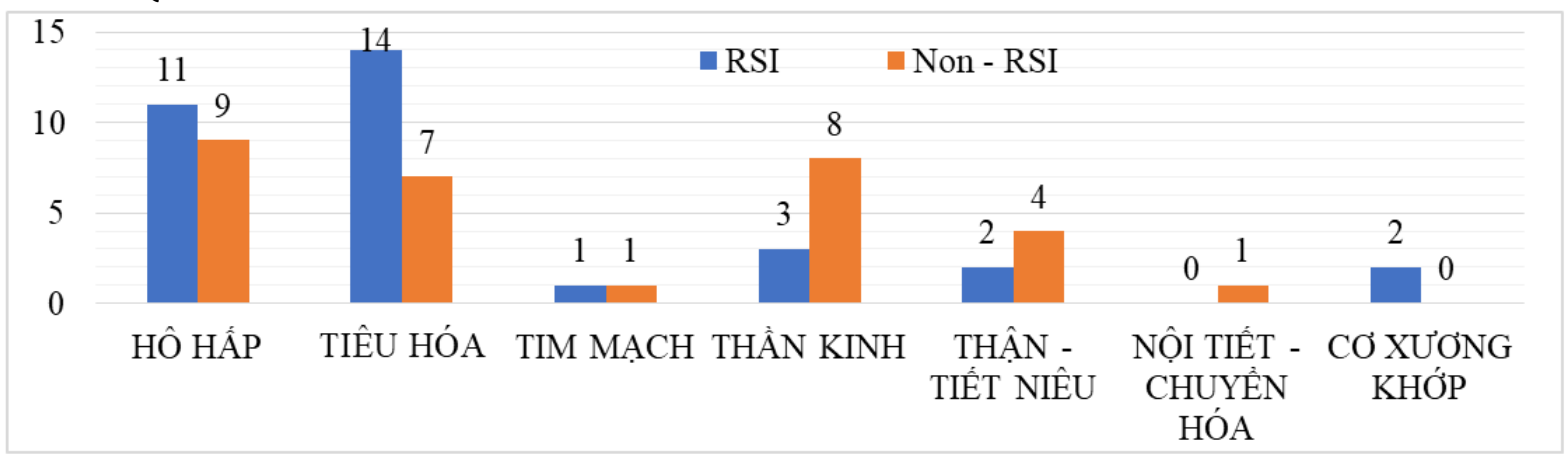

Biêu đồ 3.1. Phân bố bệnh nhân theo nhóm bệnh lý

Nhân xét: Hai nhóm bệnh lý phổ biến nhất là tiêu hóa và hô hấp, chiếm tỷ lệ lần lượt là 33\% và 31\%, sự phân bố bệnh nhân theo các nhóm bệnh lý là tương đương giữa nhóm bệnh nhân đặt nội khí quản theo phương pháp RSI và non - RSI.

Bảng 3.1. Các chỉ số sinh tồn của bệnh nhân trước và sau đặt nội khí quản

\begin{tabular}{|c|c|c|c|c|c|c|}
\hline \multirow[t]{2}{*}{$x_{x}$} & \multicolumn{2}{|c|}{ RSI } & \multirow[b]{2}{*}{$\mathbf{P}$} & \multicolumn{2}{|c|}{ Non - RSI } & \multirow[b]{2}{*}{ p } \\
\hline & $\begin{array}{c}\text { Trước } \\
(\bar{x} \pm s)\end{array}$ & $\stackrel{\text { Sau }}{(\bar{x} \pm s)}$ & & $\begin{array}{c}\text { Trước } \\
(\bar{x} \pm s)\end{array}$ & $\stackrel{\text { Sau }}{(\bar{x} \pm s)}$ & \\
\hline Mạch (chu kỳ/phút) & $117 \pm 23$ & $119 \pm 23$ & 0,10 & $114 \pm 20$ & $120 \pm 22$ & 0,02 \\
\hline
\end{tabular}




\begin{tabular}{|c|c|c|c|c|c|c|}
\hline Huyết áp tối đa $(\mathrm{mmHg})$ & $119 \pm 28$ & $120 \pm 28$ & 0,51 & $122 \pm 33$ & $105 \pm 32$ & 0,00 \\
\hline Huyết áp tối thiểu $(\mathrm{mmHg})$ & $73 \pm 16$ & $72 \pm 17$ & 0,82 & $73 \pm 17$ & $63 \pm 19$ & 0,00 \\
\hline Huyết áp trung bình $(\mathrm{mmHg})$ & $88 \pm 20$ & $88 \pm 20$ & 0,78 & $89 \pm 22$ & $77 \pm 23$ & 0,00 \\
\hline $\mathrm{SpO}_{2}(\%)$ & $98 \pm 1$ & $94 \pm 6$ & 0,00 & $98 \pm 1$ & $96 \pm 3$ & 0,01 \\
\hline
\end{tabular}

Nhận xét: Mạch, huyết áp của nhóm RSI trước và sau đặt nội khí quản không có sự khác biệt có ý nghĩa thống kê $(p>0,05)$. Mặt khác, chỉ số huyết áp của nhóm non - RSI sau đặt thấp hơn so với trước đặt và sự khác biệt này có ý nghĩa thống kê $(p<0,05)$.

$\mathrm{SpO}_{2}$ ngay sau đặt nội khí quản của cả 2 đều thấp hơn trước đặt và sự khác biệt này có ý nghĩa thông kê $(\mathrm{p}<0,05)$.

Bảng 3.2. Số lân thực hiện đặt nội khí quản

\begin{tabular}{|c|c|c|c|}
\hline Lấm & $\begin{array}{c}\text { Lân 1 } \\
\text { N (\%) }\end{array}$ & $\begin{array}{c}\text { Lần 2 } \\
\text { N (\%) }\end{array}$ & $\begin{array}{c}\text { Lân 3 } \\
\text { N (\%) }\end{array}$ \\
\hline Nhóm RSI & $29(88 \%)$ & $4(12 \%)$ & $0(0 \%)$ \\
\hline $\begin{array}{c}\text { Nhóm non - } \\
\text { RSI }\end{array}$ & $20(67 \%)$ & $8(26 \%)$ & $2(7 \%)$ \\
\hline
\end{tabular}

Nhận xét: Các bệnh nhân đặt nội khí quản theo phương pháp RSI đều được đặt nội khí quản thành công trong 1 hoặc 2 lần, còn nhóm non - RSI có $7 \%$ cần đặt tới lần thứ 3 . Tỷ lệ đặt nội khí quản thành công lần đầu theo phương pháp RSI là $88 \%$ cao hơn so với non - RSI là $67 \%$, sự khác biệt này có ý nghĩa thống kê $(p<0,05)$.

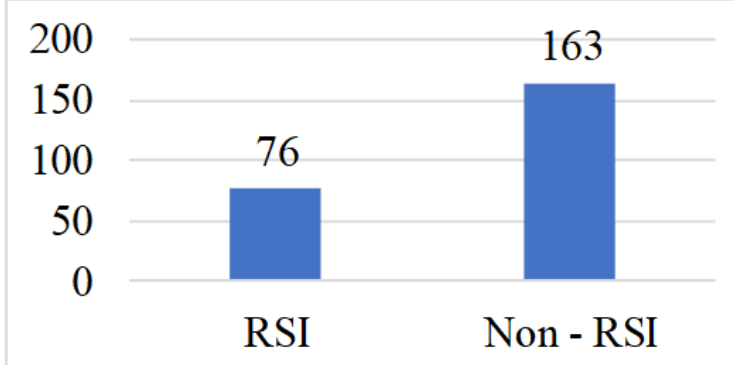

Biểu đồ 3.2. Thời gian đặt nội khí quản của hai nhóm bênh nhân

Nhận xét: Thời gian đặt nội khí quản trung bình của nhóm đặt bằng phương pháp RSI là 76 giây ngắn hơn so với nhóm non - RSI là 163 giây, sự khác biệt này có ý nghĩa thống kê $(p<0,05)$.

Bảng 3.3. Các biến cố xảy ra trong quá trinh đặt nội khí quản

\begin{tabular}{|c|c|c|c|}
\hline Loại biến cố & $\begin{array}{c}\text { Nhóm } \\
\text { RSI } \\
(\mathbf{N}-\mathbf{\%})\end{array}$ & $\begin{array}{c}\text { Nhóm } \\
\text { non - RSI } \\
(\mathbf{N}-\mathbf{\%})\end{array}$ & $\mathbf{p}$ \\
\hline $\begin{array}{c}\text { Tổn thương miệng, } \\
\text { họng }\end{array}$ & $1(3,0 \%)$ & $3(10,0 \%)$ & 0,34 \\
\hline Đặt vào thực quản & $0(0 \%)$ & $1(3,3 \%)$ & 0,47 \\
\hline Đăăt quá sâu & $0(0 \%)$ & $1(3,3 \%)$ & 0,47 \\
\hline Trào ngược, nôn & $0(0 \%)$ & $3(10,0 \%)$ & 0,10 \\
\hline Tụt huyết áp & $2(6,1 \%)$ & $11(36,7 \%)$ & 0,03 \\
\hline Rách cuff & $0(0 \%)$ & $1(3,3 \%)$ & 0,47 \\
\hline Tụt SpO2 & $5(15,1 \%)$ & $2(6,7 \%)$ & 0,43 \\
\hline Ngừng tuần hoàn & $0(0 \%)$ & $0(0 \%)$ & \\
\hline
\end{tabular}

Nhận xét: Tỷ lệ tự huyết áp trong quá trình đăt nội khí quản ở nhóm non - RSI là cao hơn so với nhóm RSI và sự khác biệt này có ý nghĩa thống kê $(p<0,05)$.

Các biến cố: tổn thương miệng, họng, đặt nội khí quản quá sâu, đặt nội khí quản vào thực quản, trào ngược, nôn, rách cuff trong quá trình thực hiện xảy ra ở nhóm đặt nội khí quản theo phương pháp non - RSI nhiều hơon so với nhóm đặt nội khí quản theo phương pháp RSI, tuy nhiên sự khác biệt chưa có ý nghĩa thống kê $(p>0,05)$.

Tỷ lệ tụt $\mathrm{SpO}_{2}$ trong quá trình đặt nội khí quản ở nhóm RSI cao hơn so với nhóm non RSI, tuy nhiên sự khác biệt này chưa có ý nghĩa thống kê $(p>0,05)$.

\section{BÀN LUẬN}

Trong nghiên cứu của chúng tôi, nhóm bệnh lý phổ biến là bệnh lý tiêu hóa và hô hấp với tỷ lệ $33 \%$, và $21 \%$. Tỷ lệ này khác biệt so với các nghiên cứu khác. Nghiên cứu của Yamakana (2019) các nhóm bệnh lý thường gặp là thần kinh chiếm $55 \%$, tim mạch $10,4 \%^{3}$ còn trong nghiên cứu của Masashi Okubo (2017) ${ }^{4}$, nhóm chấn thương chiếm hàng đâuu với tỷ lệ $23 \%$. Sở dĩ có sự khác biệt này do sự khác biệt về các mặt bệnh giữa các trung tâm cấp cứu khác nhau. Nghiên cứu của chúng tôi thực hiện tại Trung tâm cấp cứu $A 9$ Bệnh viện Bạch Mai, các bệnh lý thường gặp nhất là xuất huyết tiêu hóa, viêm phổi, đợt cấp COPD, viêm tụy cấp, các cấp cứu ngoại khoa như chấn thương, bỏng chiếm tỷ lệ thấp hơn.

Qua nghiên cứu, chúng tôi thấy trong nhóm đặt nội khí quản theo phương pháp RSI, các chỉ số sinh tồn như mạch, huyết áp không thay đổi nhiều giữa trước và sau thủ thuật. Mặt khác, nhóm đặt nội khí quản theo phương pháp không dùng giã்n cớ, huyết áp sau đặt nội khí quản có xu hướng thấp hơn so với trước đặt nội khí quản.

Sở dĩ có sự chênh lệch này có lẽ do tác dụng của thuốc an thần, giãn cơ dùng trong quá trình đặt nội khí quản. Nhóm bệnh nhân đặt nội khí quản theo phương pháp RSI được dùng an thần 
ketamine và giãn cơ rocuronium. Ketamine gây tăng tiết catecholamine, ít ảnh hưởng đến huyết động, trừ trường hợp sốc mất bù, giảm co bóp cớ tim. Nhóm bệnh nhân đặt nội khí quản non RSI được dùng an thần propofol, midazolam, đây là các thuốc có ảnh hưởng đến huyết động, đặc biệt những bệnh nhân nặng, có huyết áp không ổn định từ trước. Hơn nữa, nhóm bệnh nhân này không dùng giãn cớ, vì vậy liều an thần của bệnh nhân cần dùng có xu hướng cao hơn để đảm bảo quá trình đặt nội khí quản được thuân lợi. Nhiều bệnh nhân trong nghiên cứu của chúng tôi phải dùng thêm an thần hoăcc đổi an thần trong quá trình đặt nội khí quản. Vì dùng liều an thần cao hơn đáng kể nên tác động của an thần với huyết động của bệnh nhân là rất lớn, dẫn đến thay đổi về mạch, huyết áp trong quá trình thực hiện thủ thuât.

Trong nghiên cứu, nhóm đặt nội khí quản theo phương pháp RSI chỉ cần 1 hoặc 2 lần đặt, có 2 bệnh nhân nhóm non - RSI cần đặt nội khí quản đến lần đặt thứ ba. Tỷ lệ thành công lần đâu của nhóm đặt nội khí quản theo phương pháp RSI cao hơn so với nhóm không dùng giãn cơ. Điều này tương tự với các nghiên cứu trước đó trên thế giới, như nghiên cứu của Kerslake (2015), tỷ lệ thành công lần đâuu cúa nhóm RSI là $87 \%$ và nhóm non - RSI là $78 \% \%^{5}$, nghiên cứu ảa Driver (2020), tỷ lệ này lân lượt là $90 \%$ và $71 \% 6$.

Ngoài ra, thời gian đặt nội khí quản trung bình của nhóm đặt bằng phương pháp RSI là 76 giây ngắn hơn so với nhóm non - RSI là 163 giây với sự khác biệt có ý nghĩa thống kê.

Sở dĩ có sự khác biệt về tỷ lệ thành công trong lần đặt đầu tiên và thời gian đặt giữa hai nhóm có lẽ do bệnh nhân được đặt nội khí quản theo phương pháp RSI dùng thuốc giãn cơ, làm bệnh nhân liệt hoàn toàn cớ, mềm hoàn toàn lúc bác sĩ thực hiện thủ thuật. Ngược lại, những bệnh nhân không dùng giã̃n cơ có thể gặp tình huống an thần chưa đủ sâu, bệnh nhân còn kích thích lúc làm thủ thuật dẫn tới khó khăn, cần dùng thêm an thần hoặc giãn cơ trong quá trình thực hiên thủ thuât. Viểc thủ thuât diễn ra nhanh chóng, thuận lợi giúp bệnh nhẩn được bảo vệ đường thở, cung cấp oxy sớm, đồng thời cũng tránh được rất nhiều tai biến có thể xảy ra khi kéo dài thời gian đặt nội khí quản như tụt $\mathrm{SpO}_{2}$, tụt huyết áp do dùng an thần, tổn thương niêm mạc miệng họng, răng. Hơn nữa, việc thực hiện thủ thuật thuận lợi giúp tiết kiệm thời gian và nhân lực, góp phẩn giúp việc điều trị, theo dõi bệnh nhân hiệu quả hơn.

Như mọi thủ thuật, đặt nội khí quản cũng xảy ra rất nhiều biến cố từ thoáng qua đến nghiêm trọng. Nghiên cứu của chúng tôi có điểm giống và khác các nghiên cứu trên thế giới về các loại biến cố trong đặt nội khí quản cấp cứu, cụ thể như sau:

- Tổn thương niêm mạc miệng, họng, chúng tôi gặp 3\% bệnh nhân đặt nội khí quản theo phương pháp RSI và $10 \%$ nhóm không dùng giãn cớ, tuy nhiên sự khác biệt không có ý nghĩa thống kê $(p>0,05)$. Nghiên cứu của Masashi Okubo (2017) tại Nhật Bản, tỷ lệ tổn thương miệng của nhóm non - RSI là $4,5 \%$, cao gấp gần 3 lần so với nhóm RSI là 1,7\% ${ }^{4}$.

- Về đặt nội khí quản vào thực quản, đặt nội khí quản quá sâu, tỷ lệ gặp trong nghiên cứu rất thấp, chỉ 1 bệnh nhân trong các bệnh nhân đặt nội khí quản không dùng giãn cớ, không gặp trong nhóm đặt nội khí quản theo phương pháp RSI. Tương tự, nghiên cứu của Masashi Okubo (2017), tỷ lệ đặt nội khí quản vào thực quản cũng thấp: 3,5\% ở nhóm RSI và 4,8\% ở nhóm non - RSI, còn đặt nội khí quản quá sâu, vào phế quản gốc, tỷ lệ này là $1,8 \%$ ở nhóm RSI và $1,3 \%$ ở nhóm non - RSI ${ }^{4}$.

- Về biến cố trào ngược, nôn, tỷ lệ biến cố này ở nhóm RSI thấp hớn so với nhóm non RSI, tương tự với nghiên cứu của Kerslake với tỷ lệ ở 2 nhóm RSI và non - RSI lần lượt là $0,7 \%$ và $3 \%{ }^{5}$ hay nghiên cứu của Masashi Okubo (2017) với tỷ lệ là $1,0 \%$ và $2,2 \%{ }^{4}$.

- Bệnh nhân đặt nội khí quản theo phương pháp RSI có tỷ lệ tưt $\mathrm{SpO}_{2}$ cao hơn so với nhóm không dùng giãn cớ. Sự khác biệt này có lẽ đến từ tác dụng của giãn cớ làm bệnh nhân liệt toàn bộ cớ, bao gồm các cơ hô hấp, dẫn tới việc thông khí cho bệnh nhân cũng khó khăn hơn. Chính vì vậy, quá trình dự trữ oxy đối với bệnh nhân đặt nội khí quản theo phương pháp RSI là rất quan trọng, nhằm hạn chế được tình trạng tụt $\mathrm{SpO}_{2}$ cũng như các biến cố tuần hoàn, hô hấp xảy ra trong quá trình thực hiện thủ thuật.

- Tỷ lệ tụt huyết áp trong nhóm đặt nội khí quản theo phương pháp RSI thấp hởn so với nhóm non - RSI và sự khác biệt này có ý nghĩa thống kê. Có lẽ do nhóm bệnh nhân đặt nội khí quản theo phương pháp RSI sử dụng an thần ketamine và giãn cơ rocuronium ít ảnh hưởng đến huyết động hơn so với nhóm còn lại dùng an thần midazolam và propofol. Hơn nữa ở nhóm bệnh nhân không dùng giãn cơ, liều an thần của bểnh nhân cần dùng có xu hướng cao hơn để đảm bảo quá trình đặt nội khí quản được thuận lợi, có nhiều bệnh nhần dùng thêm an thần trong quá trình đặt nội khí quản, dẫn tới tăng nguy cơ 
tụt huyết áp trong lúc thực hiện thủ thuật.

\section{KẾT LUẬN}

Phương pháp đặt nội khí quản nhanh theo trình tự với ketamine và rocuronium áp dụng với những bệnh nhân cấp cứu không có yếu tố tiên lượng đường thở khó làm giảm thời gian thực hiện thủ thuật, tăng tỷ lệ thành công trong lẩn đặt đâu tiên và không làm tăng nguy cơ các biến cổ nghiêm trọng trong quá trình thực hiện so với những bệnh nhân đặt nội khí quản không dùng giãn cơ.

\section{TÀI LIÊU THAM KHẢO}

1. Mace SE, Ducharme J, Murphy MF, eds. Pain Management and Sedation: Emergency Department Management. New York: McGraw-Hill, Medical Pub. Division; 2006.

2. Reed MJ. Can an airway assessment score predict difficulty at intubation in the emergency department? Emergency Medicine Journal.
2005;22(2):99-102

3. Yamanaka S, Goldman RD, Goto T, Hayashi H. Multiple intubation attempts in the emergency department and in-hospital mortality: A retrospective observational study. Am J Emerg Med. 2020;38(4):768-773.

4. On behalf of the Japanese Emergency Medicine Network Investigators, Okubo M, Gibo K, Hagiwara Y, Nakayama Y, Hasegawa K. The effectiveness of rapid sequence intubation (RSI) versus non-RSI in emergency department: an analysis of multicenter prospective observational study. Int J Emerg Med. 2017;10(1):1.

5. Kerslake D, Oglesby AJ, Di Rollo N, James E, McKeown DW, Ray DC. Tracheal intubation in an urban emergency department in Scotland: A prospective, observational study of 3738 intubations. Resuscitation. 2015;89:20-24.

6. Driver $B E$, Prekker ME, Reardon RF, et al. Success and Complications of the Ketamine-Only Intubation Method in the Emergency Department. The Journal of Emergency Medicine. 2021;60(3):265-272.

\section{TRẦM CẢM THEO THANG DASS 21 Ở SINH VIÊN HỆ BÁC SĨ Y KHOA NĂM THỨ NHẤT TRƯỜNG ĐAI HỌC Y HÀ NộI NĂM HỌC 2020-2021 VÀ MộT SỔ YẾU TỐ LIÊN QUAN}

\section{Lê Thị Vũ Huyền*}

\section{TÓM TẮT}

Nghiên cứu nhằm xác định tỷ lệ nguy cơ trâm cảm và một số yếu tố liên quan đến trẩm cảm ở sinh viên năm thứ nhất hệ bác sĩ y khoa trường Đại học $Y$ Hà Nội năm học 2020-2021. Nghiên cứu mô tả cắt ngang trên 345 sinh viên, công cụ để đánh giá trầm cảm là thang DASS 21 . Kết quả cho thấy $52,8 \% \%$ sinh viên có nguy cơ mắc trầm cảm. Trong đó trầm mức độ nhe: $20,6 \%$, trầm cảm mức độ vừa: $18,6 \%$, trầm cảm mức độ nặng: 6,7\%, rất nặng: 7,0\%. Các yếu tố liên quan đến nguy cơ trầm cảm ở sinh viên năm thứ nhất hệ bác sĩ Y khoa là: không hài lòng với ngoai hình, khó khăn với tài chính, tập thể dục, xung đột với bạn cùng phòng, giảm sức khỏe bản thân, chấn thướng ốm nă̆ng, một thành viên trong gia đình bị bệnh nặng, điểm học không như mong đợi, thích nghi với việc học ở trường đại học

\section{SUMMARY \\ DEPRESSION ASSESSED BY DASS 21 SCALE AMONG FIRST YEAR MEDICAL DOCTOR STUDENTS AT HANOI MEDICAL}

\footnotetext{
*Trường Đại học Y Hà Nội

Chịu trách nhiệm chính: Lê Thị Vũ Huyền

Email: levuhuyen@hmu.edu.vn

Ngày nhận bài: 16.9.2021

Ngày phản biên khoa họ: 15.11.2021

Ngày duyệt bài: 23.11.2021
}

\section{UNIVERSITY IN THE 2020-2021 ACADEMIC} YEAR AND SOME ASSOCIATED FACTORS

The study aimed to determine the proportion of students experiencing depression and some factors related to depression among first-year medical doctor students at Hanoi Medical University in the academic year 2020-2021. We conducted a cross-sectional study on 345 students and used the DASS 21 scale to assess the level of depression among students. Our results showed that $52,8 \%$ of students had depression (20.6\% with mild depression, $18.6 \%$ with moderate depression, $6.7 \%$ with severe depression, $7.0 \%$ with very severe depression). Factors associated with depression among first-year medical students included dissatisfaction with appearance,financial difficulties, exercise, conflicts with roommates, reduced selfhealth, serious illness injury, a serious illness in the family, poor grades wait, adjust to studying at university

Tư khóa: Trầm cảm, sinh viên năm thứ nhất hệ Bác sĩ Y khoa, yếu tố liên quan

\section{I. ĐẶT VẤN ĐỀ}

Trầm cảm là một bệnh tâm thần đặc trưng bởi tâm trạng buồn chán và giảm hứng thú hoặc niềm vui trong việc thực hiện các hoạt động hàng ngày. ${ }^{1}$ Căn bệnh này là một trong những nguyên nhân chính gây ra tàn tật trên thế giới, ảnh hưởng đến gần 300 triệu người ở mọi lứa 